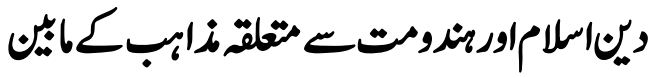 \\ مثزكر اخلاقة تليمات كاجازه
}

\section{An Overview of the Common Moral Teachings Islam and Hinduism Based Religions}

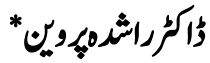

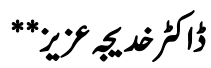

\begin{abstract}
The study of world religions makes it clear that after the basic teachings of every religion, which had came into being after the arrival of human beings in this world, the moral teachings have been given the utmost importance.
\end{abstract}

The improvement in the individual and collective life of people depends on moral education which gives them the feeling of an atmosphere of peace and tranquility in the world. The teachings of moral education also gives a sense of equality in a society in which everyone is assured of the protection of his/her rights and interests. Resultantly, in a society where the roots of "good morals" are strong, society never goes astray.

The importance of morality for the individual and collective life of human beings could be gauged by the fact that all religious leaders of the world teach their followers good morals and human rights. The moral teachings also help in distinguishing lawful, unlawful, good, and evil. The religious leaders forbid followers to do things that make them or their social life suffer in the wrong way.

Key Words: Islam, Hinduism, Moral Teachings, Human Rights.

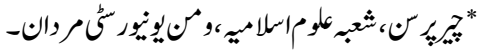

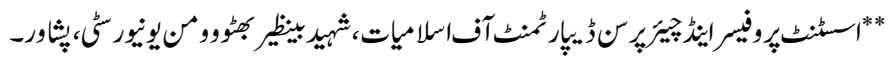




\section{لنط "اخلاق" ع لنوكواصطلاح منغوم}

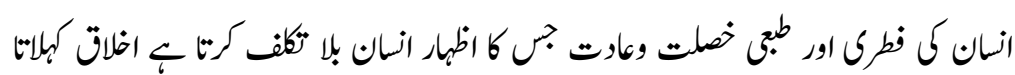

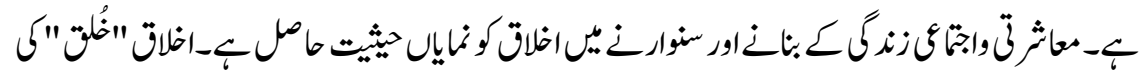

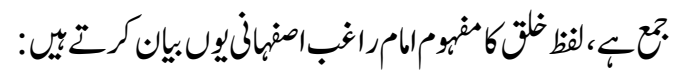

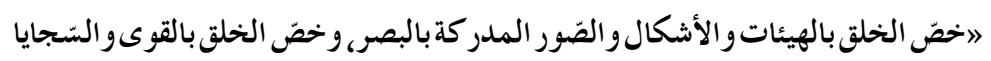
المدر كةبالبصيرةه 1

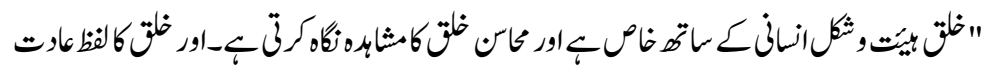

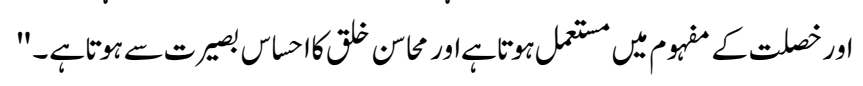

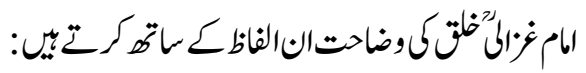

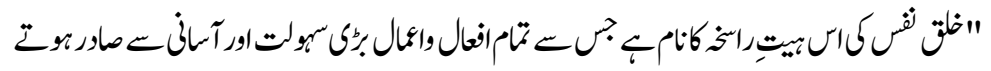

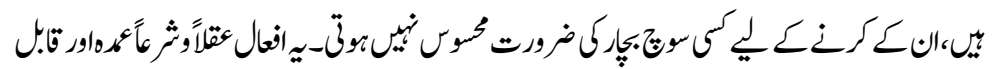

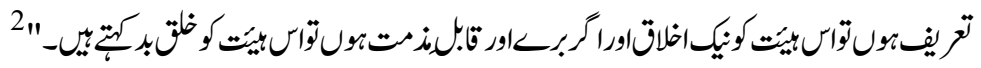

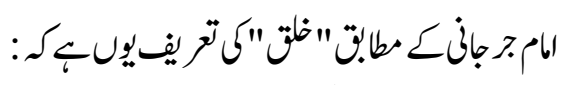

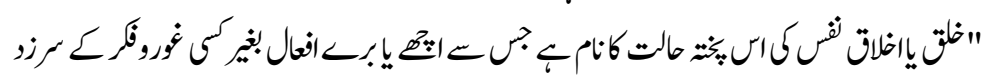

$$
\text { r" }
$$

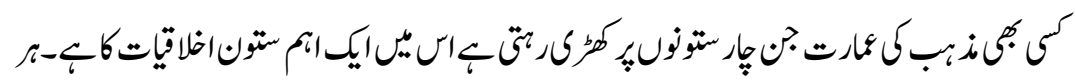

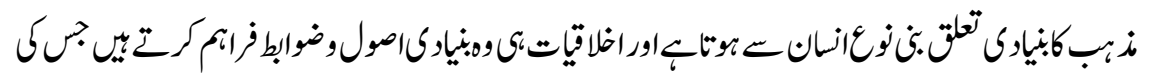

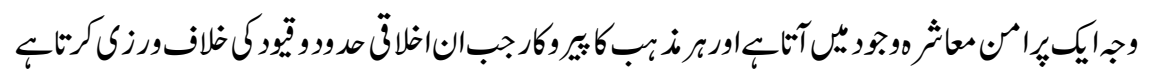

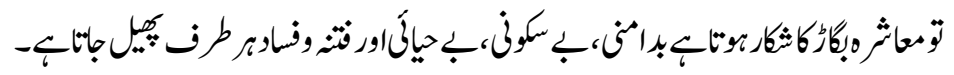

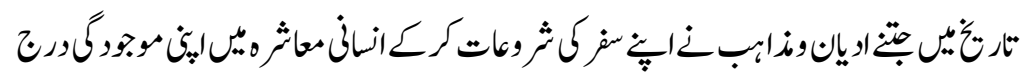

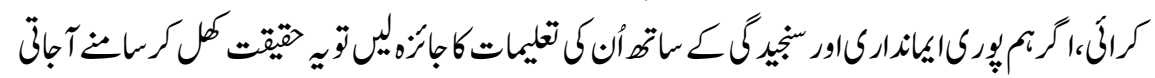

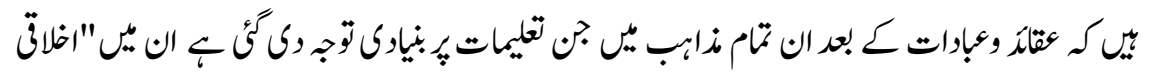

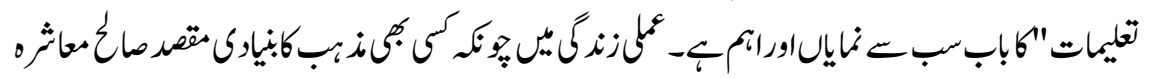

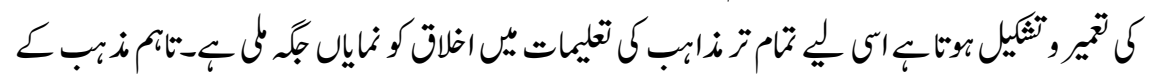




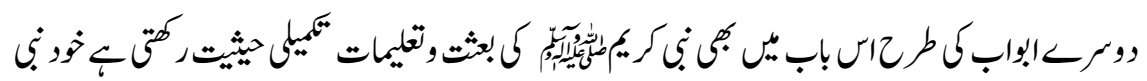

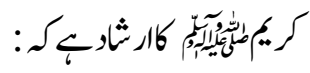
"انمابعثت لاتمم مكارمالاخحلاق《"

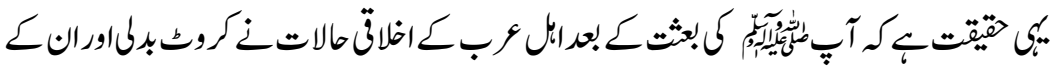

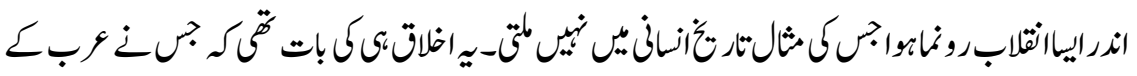

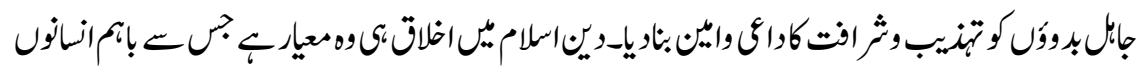

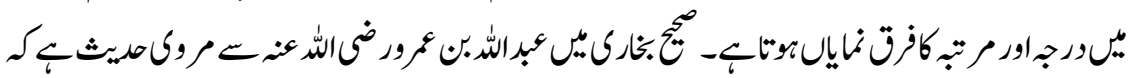

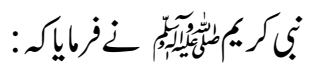

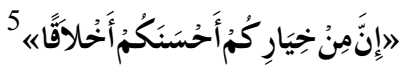

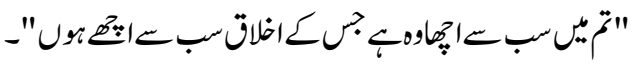

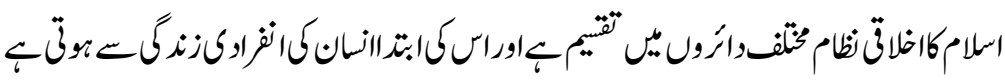

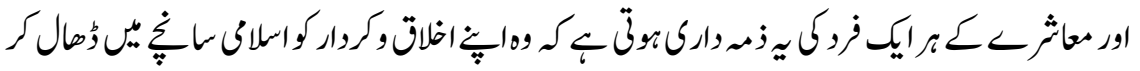

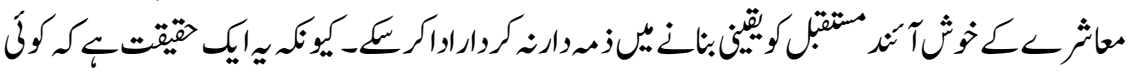

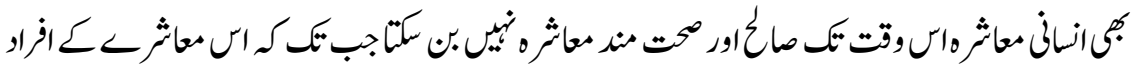

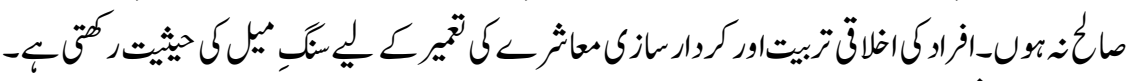

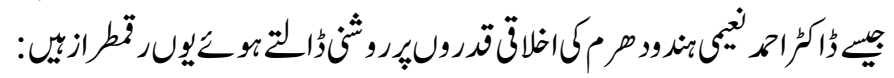

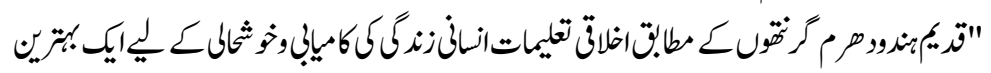

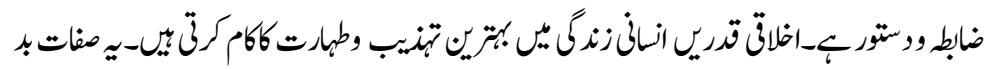

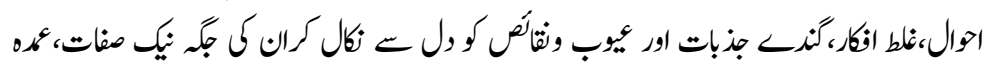

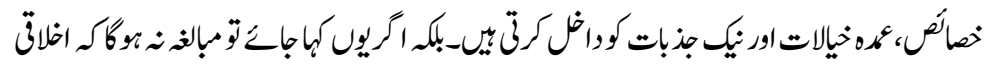

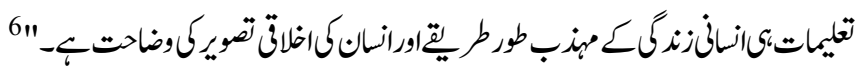

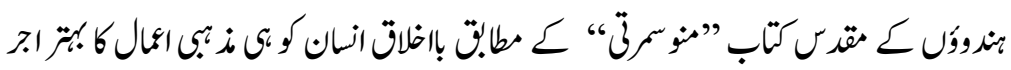

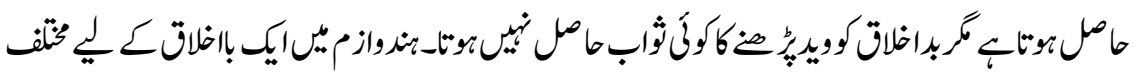

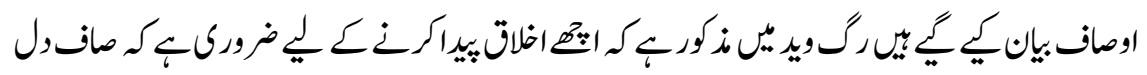

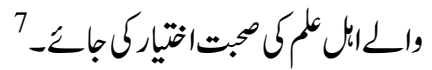




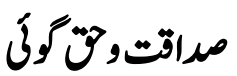

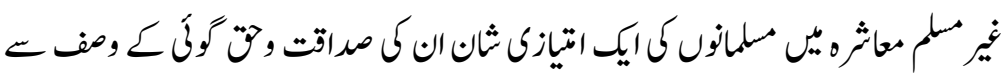

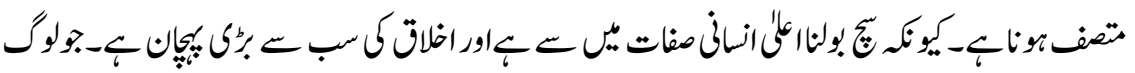

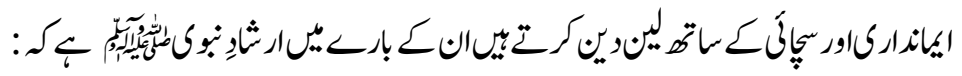

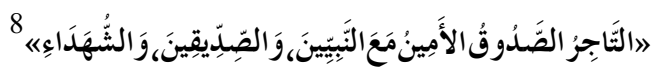

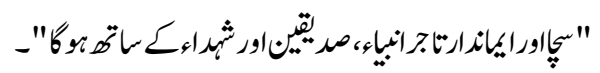

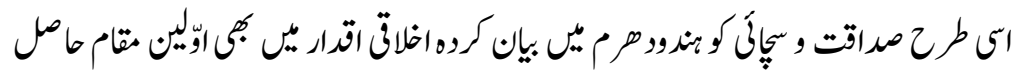

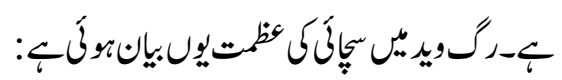

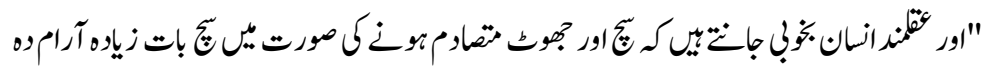

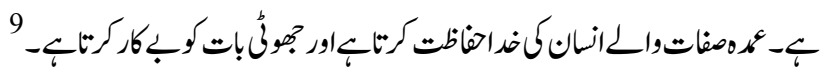

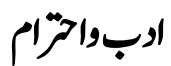

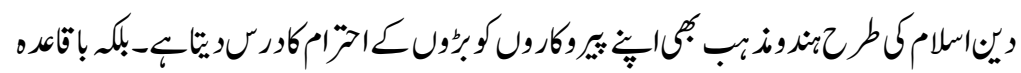

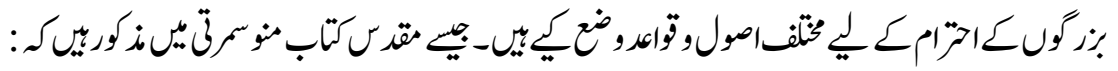

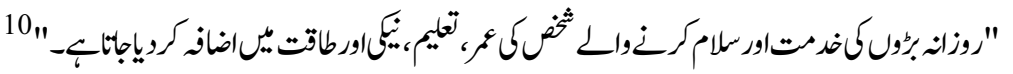

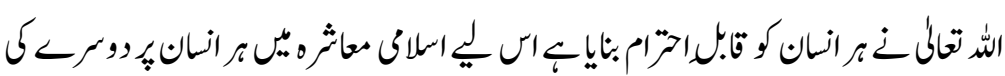

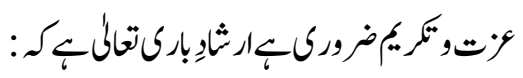

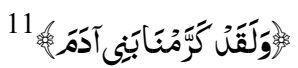

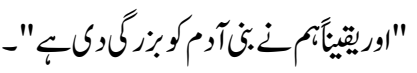

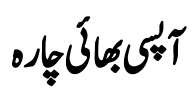

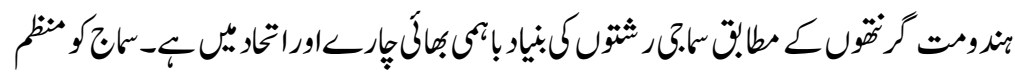

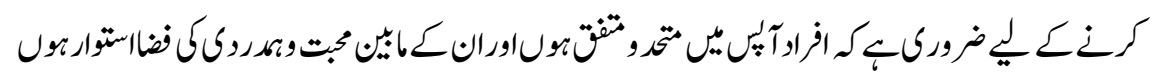

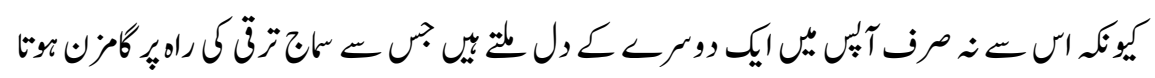

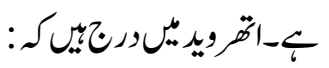




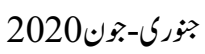

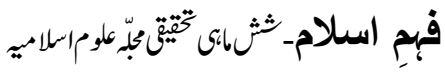

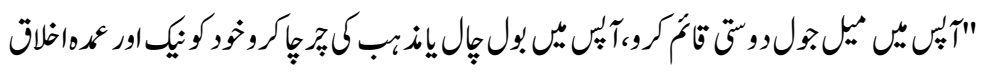

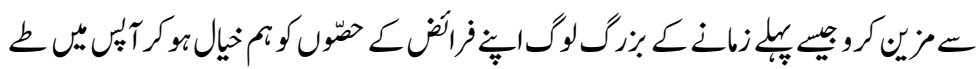

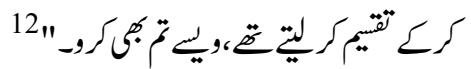

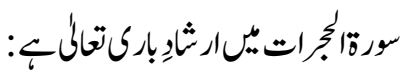

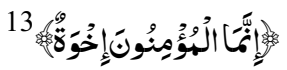

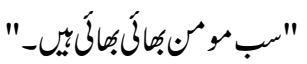

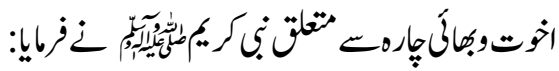

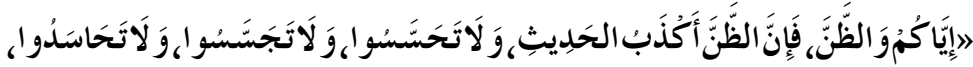

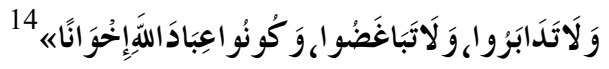

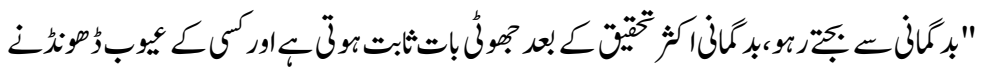

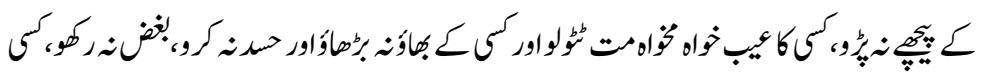

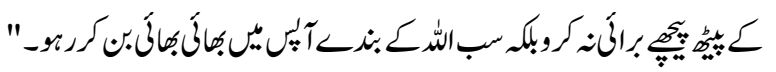

مخاورتوفئن

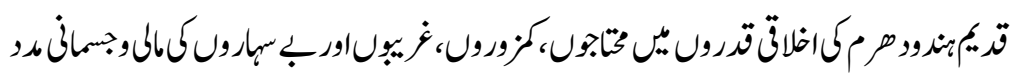

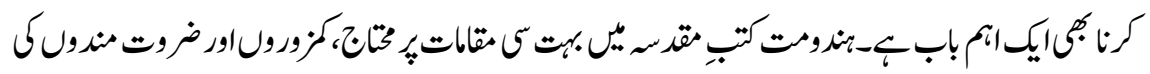

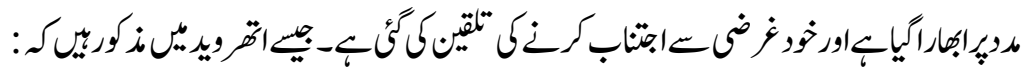

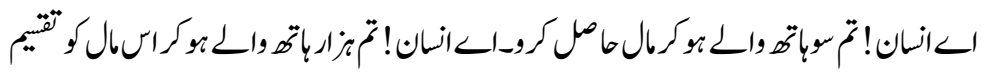

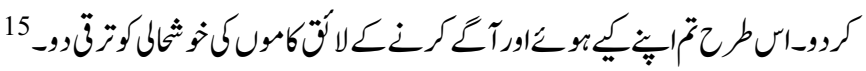

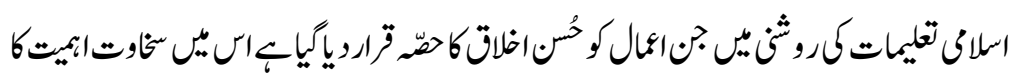

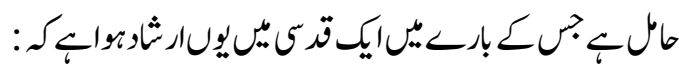

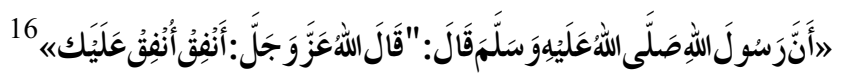

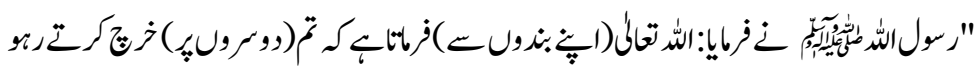

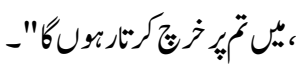

151 


\section{رنَّن}

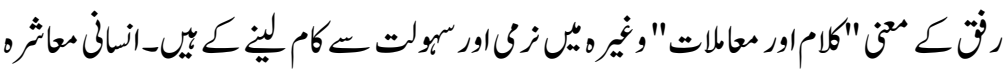

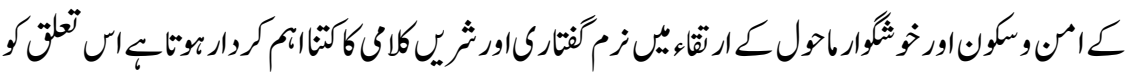

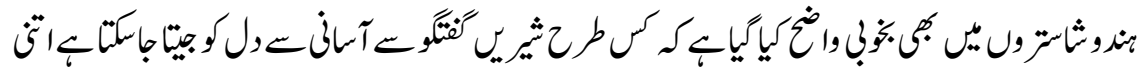

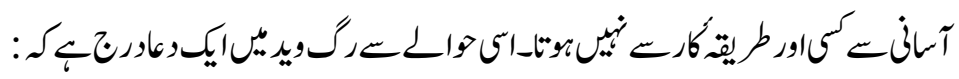

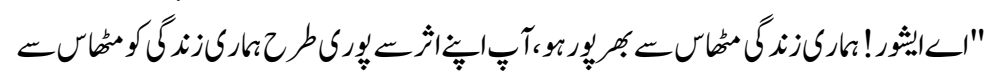

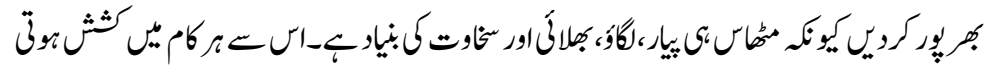
$17 "-c$

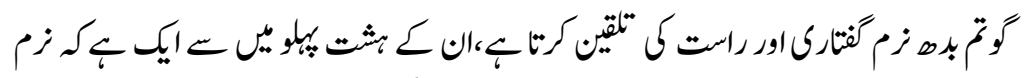

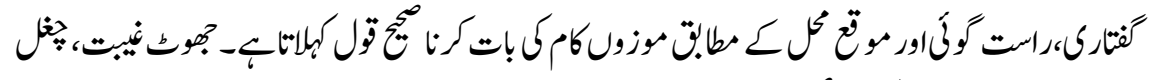

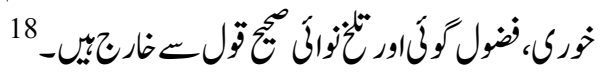

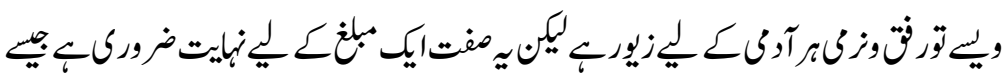

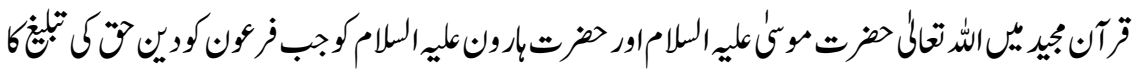

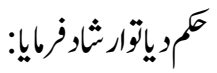

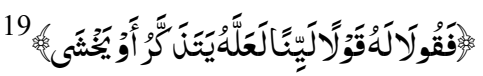

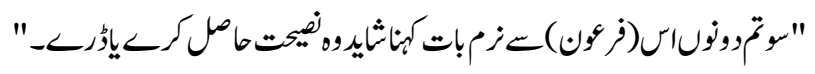

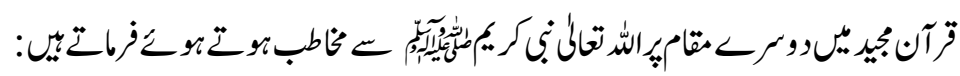

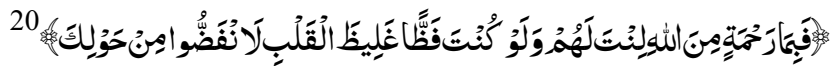

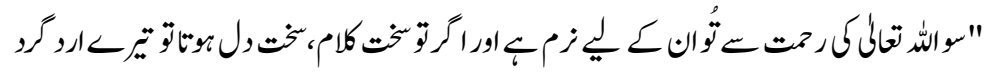

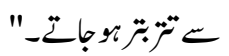

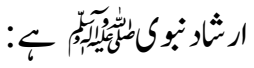

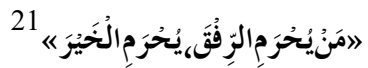

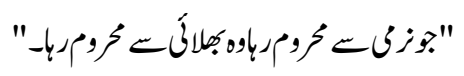




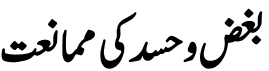

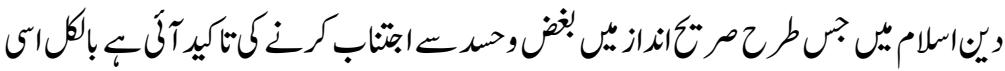

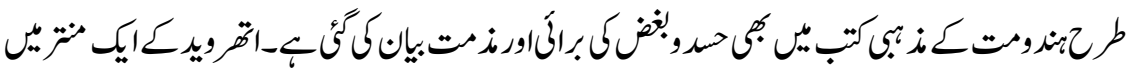

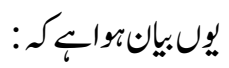

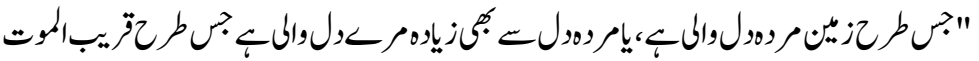
22 - 22 -

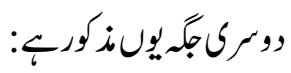

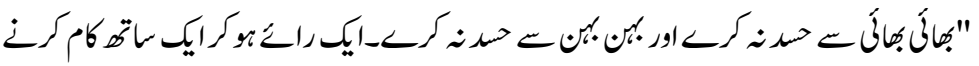
"23.

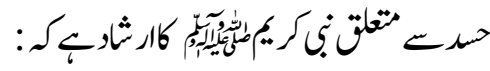

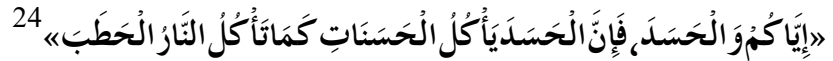

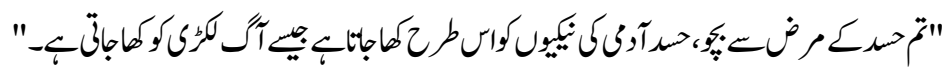

\section{عيب:وكَكماندت}

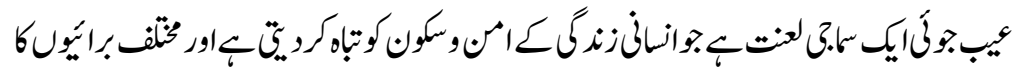

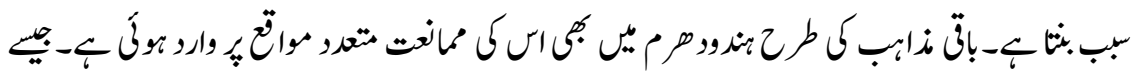

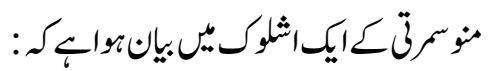

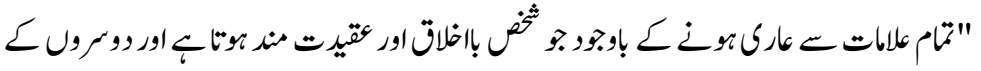

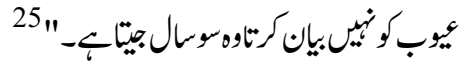

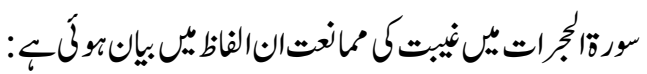

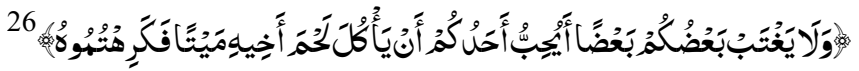

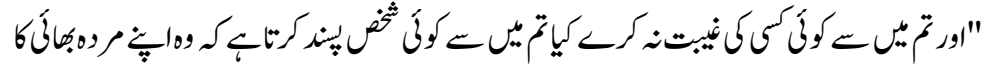
" 


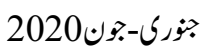

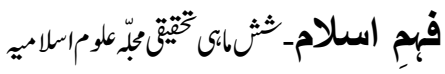

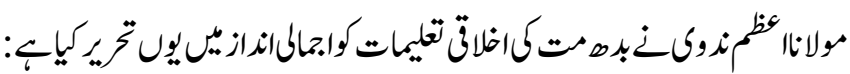

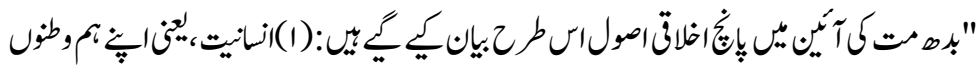

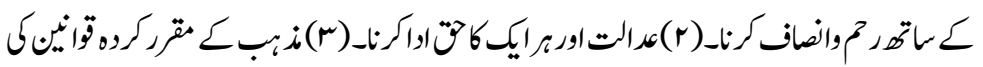

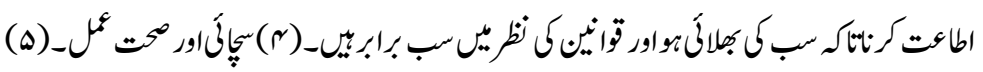

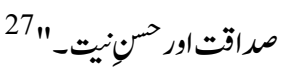

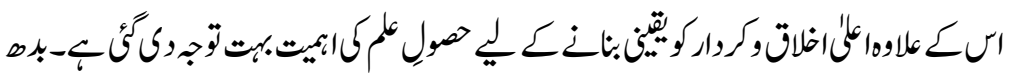

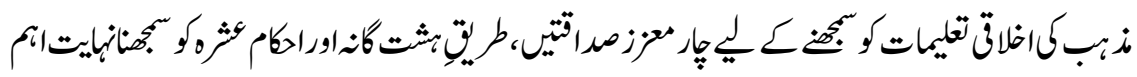

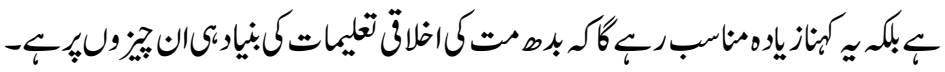

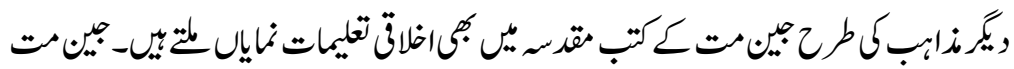

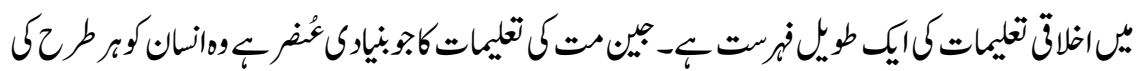

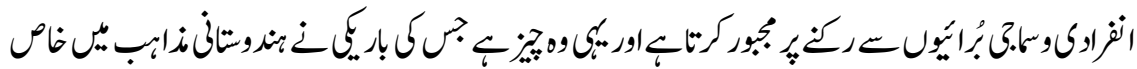

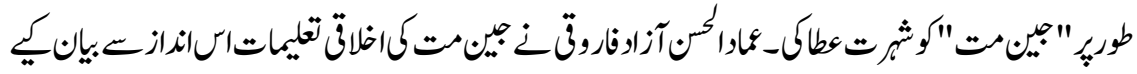

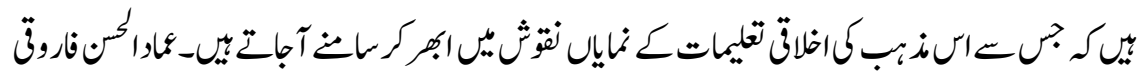

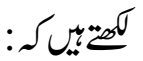

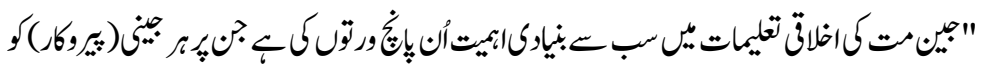

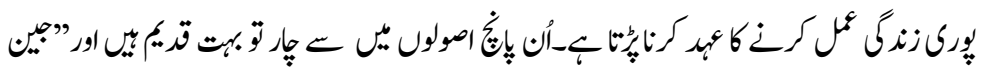

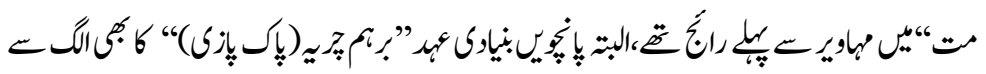

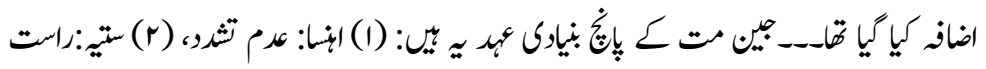

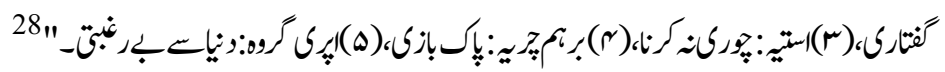

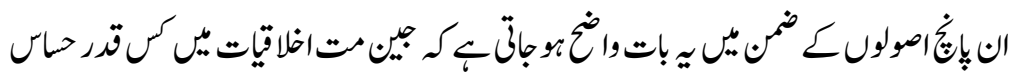

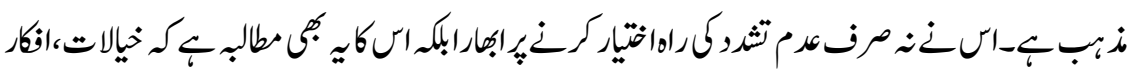

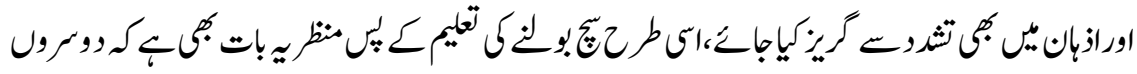

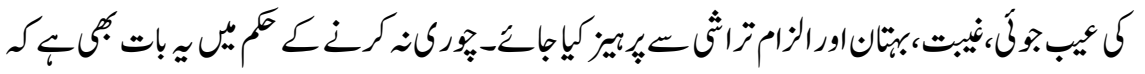

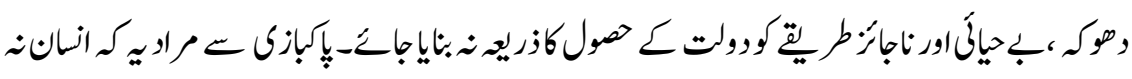




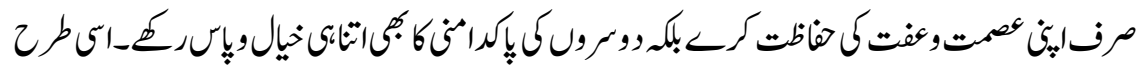

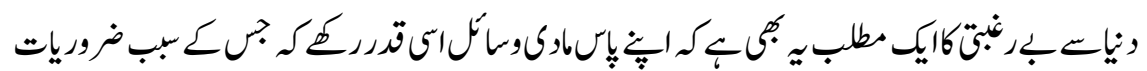
نزكاك

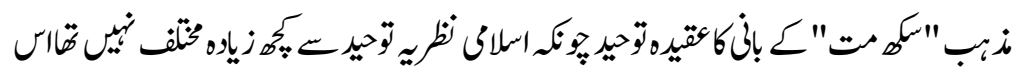

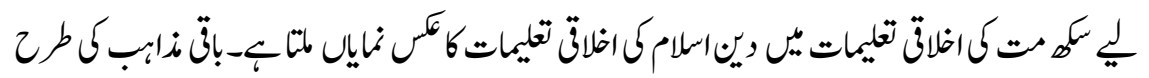

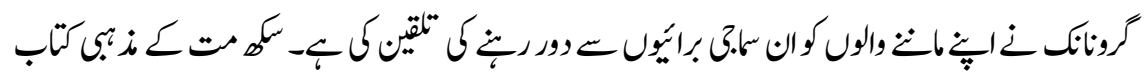

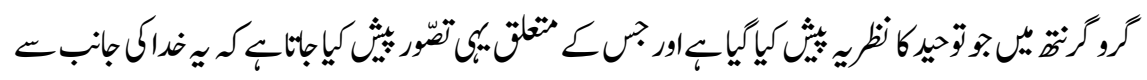

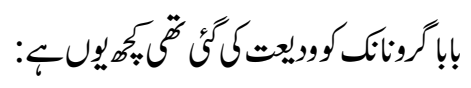

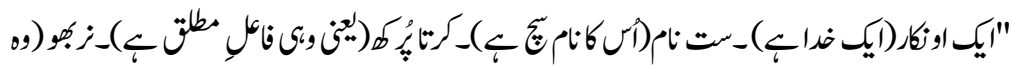

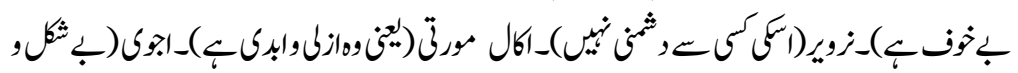

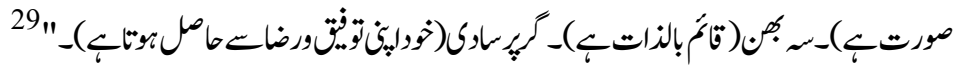

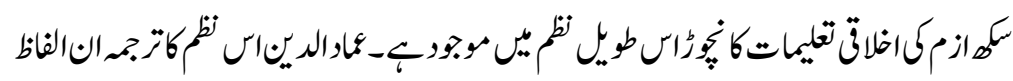

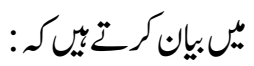

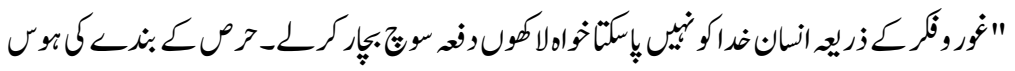

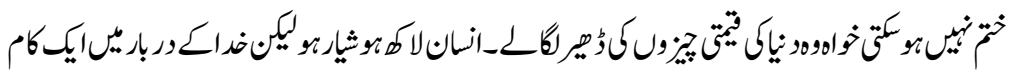

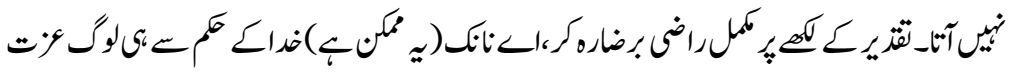

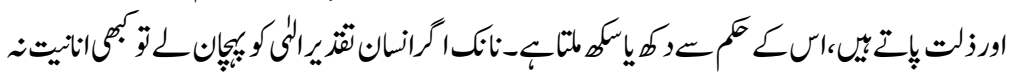
30 "_留

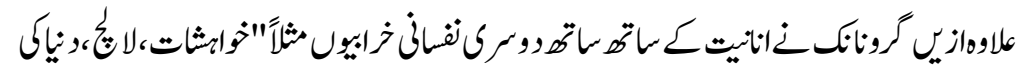

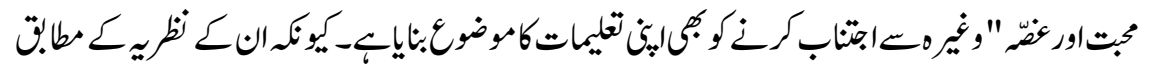

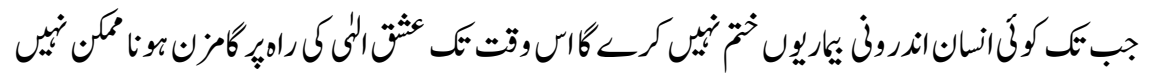

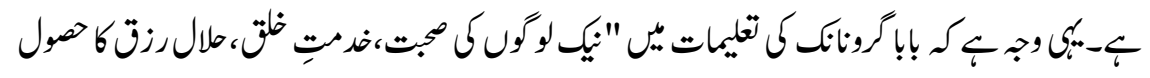

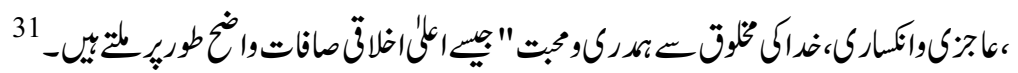




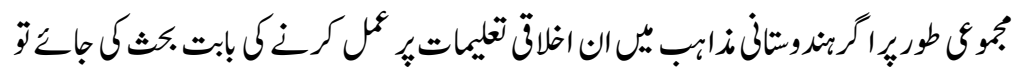

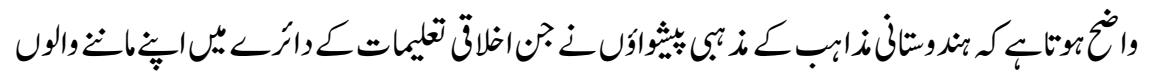

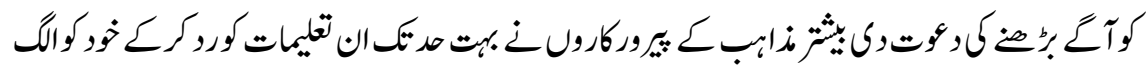

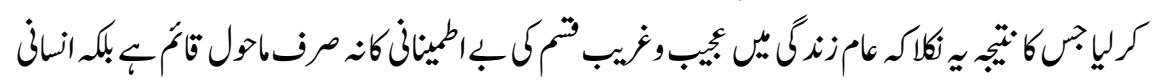

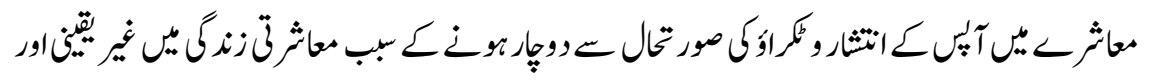

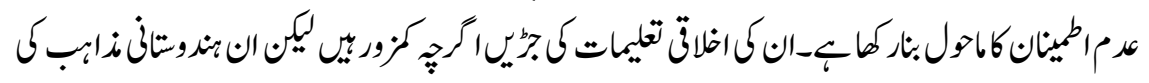

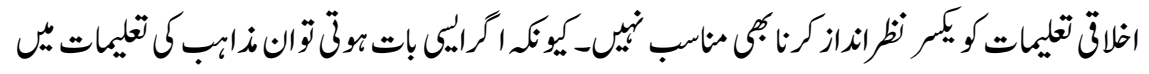

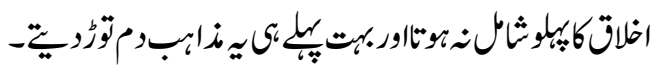

\section{ملام:كلمام}

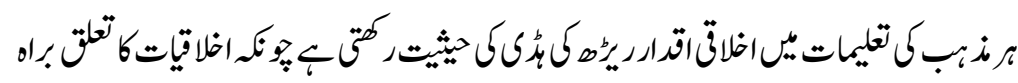

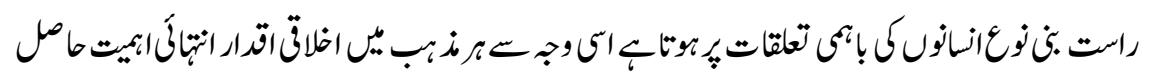

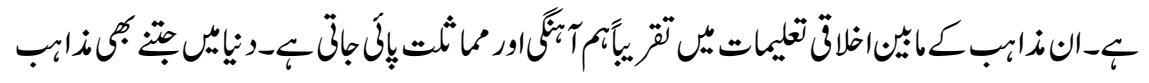

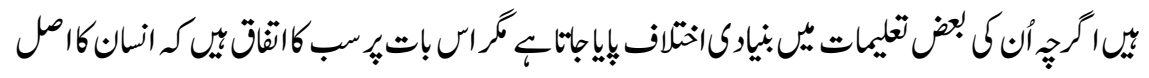

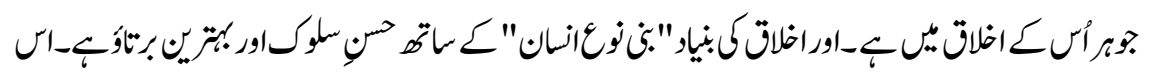

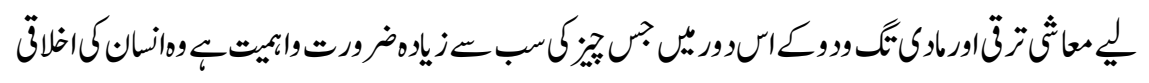

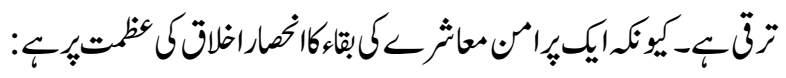

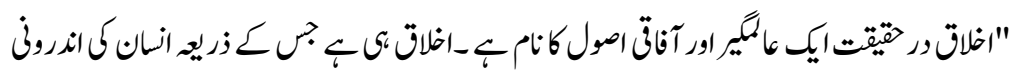

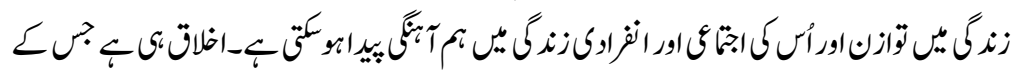

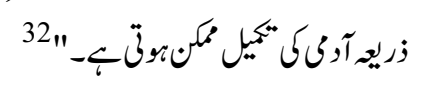

حوالد جإ

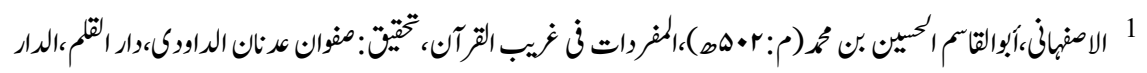

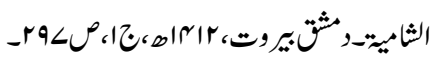




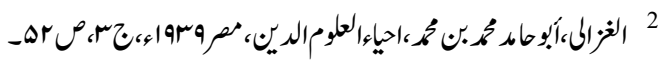

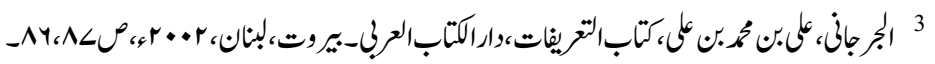
4

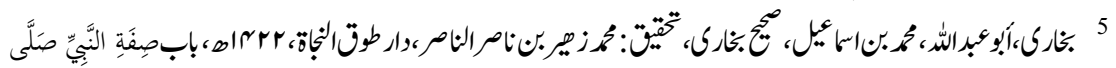

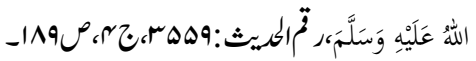

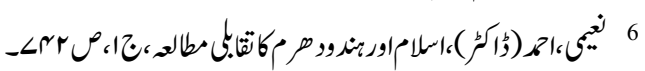

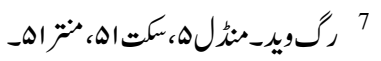

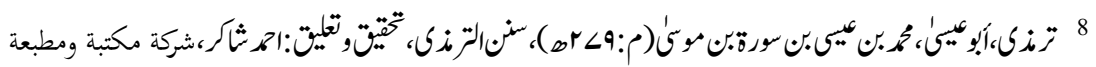

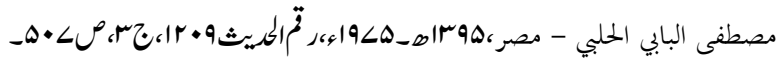

$$
\begin{aligned}
& 9
\end{aligned}
$$

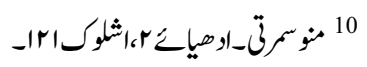

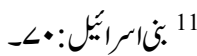

$$
\begin{aligned}
& 13
\end{aligned}
$$

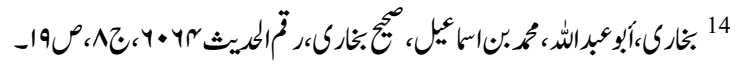

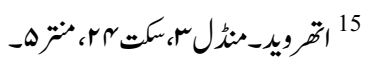

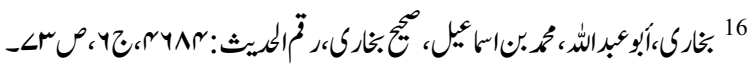

$$
17 \text { ر" } 18
$$

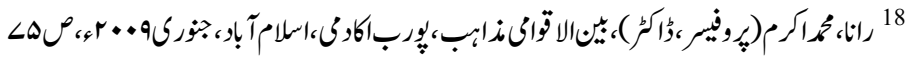

$$
-r r: p^{19}
$$

أس 20

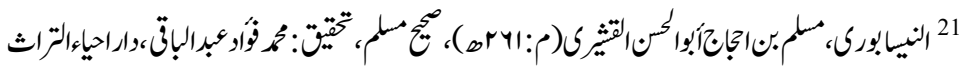

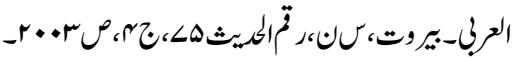

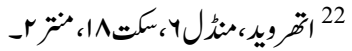

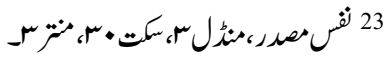

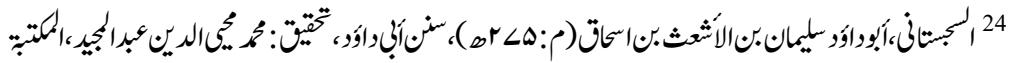

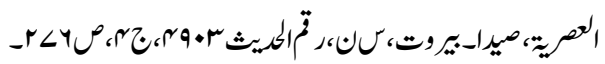




$$
\begin{aligned}
& 25 \\
& 26 \\
& 27
\end{aligned}
$$

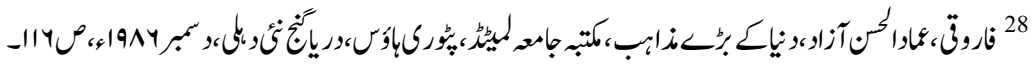
${ }^{29}$ Singh,Gupal. Dr,Guru Granth (English version),Dehli 1996,P\#5.

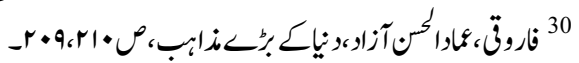

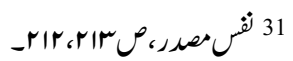

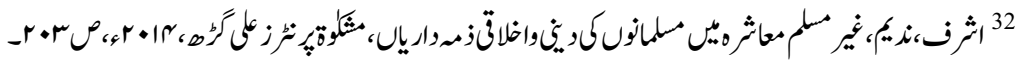

